\title{
L'home màquina «republicà» de Sunyer i Capdevila
}

\author{
Jordi Riba
}

Universitat Autònoma de Barcelona

jriba12@yahoo.com

El hombre es una máquina ${ }^{1}$

L'humanité, malgré tout, veut être immortelle $e^{2}$

Escriure contra Déu no era facil al segle XIX. Tampoc no ho és ara. Així ho demostra l'absència d'esment al procés de secularització en sengles obres de referència com ho són el diccionari Ictine $u^{3}$ i el Diccionario de pensamiento político del siglo $X I X^{4}$. Cal suposar que ambdós tindran les seves raons per defugir parlar del fet més important del procés de democratització contemporani, tal com l'ha explicat Marcel Gauchet en el seu llibre El desencantamiento del mundo. Historia politica de la religión ${ }^{5}$. En tot cas, sempre resulta curiós veure com els autors que tracten les absències d'aquests aspectes importants del pensament acaben passant per eixelebrats, heterodoxos, etc. És el cas, entre d'altres, de Francesc Sunyer i Capdevila, que amb el seu escrit Dios, publicat el 1869 i que ara veu una nova edició ${ }^{6}$, fou capaç d'esborronar fins i tot republicans de soca-rel.

Sunyer i Capdevila, empordanès, metge, polític republicà, primer alcalde electe de Barcelona, diputat a Corts, ministre de Pi i Margall, lector de Comte, dels materialistes francesos del segle XVIII, de Renan, de Cabet i dels socialistes llibertaris, que féu escriure en el seu epitafi: «Luchó contra Dios, contra los reyes y contra la tisis», posseí la valentia que dóna la lucidesa per fer d'un tema tabú, fins i tot per als no creients, un motiu de reflexió filosòfica que s'encarés amb el problema que tenien els republicans: qui substituïa Déu en l'imaginari col-lectiu.

Les idees materialistes, tal com assenyala Ramon Alcoberro en el pròleg de la nova edició, foren introduïdes pels metges humanistes i per la reflexió política progressista, mentre que la reflexió més pròpiament filosòfica en queda-

1. Sunyer Capdevila (1872) p. 17.

2. GUYAU (1889).

3. Artal, Gabriel, Lluch, Roca (1979).

4. Fernández Sebastián, Fuentes (2002).

5. GAUCHET (2006).

6. Sunyer Capdevila (2007). 
va al marge. El seguit d'exilis a què foren abocats els polítics liberals els féu conèixer a França la filosofia materialista, que varen veure com una ruptura respecte al pensament imperant fins llavors. A més, la medicina materialista ensenyada a la Universitat de Montpeller va arrelar entre els metges catalans. Sunyer, que fou metge de professió, abans d'escriure l'opuscle mencionat hagué de prendre nombroses vegades el camí de l'exili.

Aquest text de Sunyer és un escrit breu, estructurat en setze apartats en els quals l'autor explica des de les raons que l'han portat a la redacció d'un tal escrit fins a les solucions possibles, tot passant pels arguments que fan de l'existència de Déu quelcom impossible. A Sunyer trobem la mirada d'aquell que, davant les injustícies socials, creu en la possibilitat de combatre-les pels mitjans que els humans posseïm. Sunyer albirà, des d'aquesta perspectiva, el camí de l'emancipació.

L'antecedent de l'escrit de Sunyer es troba en una intervenció feta per ell mateix, com a polític republicà, a la Cambra dels Diputats a Madrid, que va tenir, pel seu contingut, ampli ressò i també importants efectes a la política espanyola. Sunyer, en la seva intervenció, feia, en clara oposició a les tesis mantingudes per Donoso Cortés, un al-legat en favor de la llibertat religiosa, inclosa la no professió de cap religió.

És cert, però, que dins del context republicà en el qual Sunyer escriu era facil associar-lo, només, amb l'anticlericalisme. I, de fet, va ser d'aquesta manera com se'l va considerar en aquell moment. Pel moviment republicà, amb el qual Sunyer estava vinculat, la barreja interessada entre l'ateisme i l'anticlericalisme, deguda a Donoso i al seu Discurso sobre dotación de culto y clero ${ }^{7}$ en el qual vincula les creences religioses amb les idees morals de tal manera que només hi ha el bé allà on hi ha creença en el més enllà, representava més un problema polític que no filosòfic.

Deixant de banda els aspectes sociològics i polítics que la intervenció de Sunyer va provocar, i que foren molts ${ }^{8}$, és evident que l'escrit, que ha estat presentat com el primer text ateu del segle XIX, encetà un camí mai recorregut en la nostra tradició, que ens porta al nucli mateix del procés de secularització que el món occidental va destapar amb la Il-lustració. Ho diu el mateix Sunyer: el seu escrit és un escrit filosòfic; per aquesta raó, es tracta d'una reflexió filosòfica que vol avançar respecte a les idees sostingudes pels materialistes del segle XVIII.

L'escrit de Sunyer és, en primer lloc, un text contra el Déu de Descartes, garant del coneixement i de tota certesa. Sunyer escriu que el pensament de l'època és l'observació pura. Es mostra com a positivista. La ciència, el saber, són indispensables per a la lluita que s'ha d'entaular permanentment contra la feblesa física, l'error en els coneixements i la perversió moral. Per a Sunyer, tot això només es pot canviar si s'adopten noves perspectives en el coneixement humà. La ciència determina l'economia, la moral i la política. En aquest context, Déu — diu Sunyer — no hi té cabuda.

8. SÁNCHEZ MARTínez (1987). 
És també un escrit contra el Déu de Leibniz, avalador del millor dels mons possibles. Sunyer, republicà, escriu que les seves idees republicanes no l'han engendrat, sinó a l'inrevés; són les idees les que han estan produïdes per ell, en oposició al context social on ha crescut. El pensament materialista que esbossa es veu completat per les idees socials sorgides de la visió d'una realitat injusta que vol canviar.

I finalment és, igualment, un escrit contra el Déu dels deistes il.lustrats, temorosos de la seva l'absència encara que sembli que se'n vulguin apartar. Sunyer afirma:

Oigo deístas exclamar asombrados o poseídos de santa ira. Qué vas a darnos a cambio de ese sentimiento que nos robas?

L'escrit de Sunyer és, fins i tot, un escrit oposat al republicanisme que té els seus orígens en Locke. Per a aquests republicans, el problema no es trobava tant en qui substituïa Déu en l'imaginari, sinó en els efectes que aquesta absència, si s'arribava a produir, tindria per a la humanitat. És el cas de J. Stuart Mill, el qual afirma sense embuts:

Mientras la vida continúe siendo insuficiente para satisfacer las aspiraciones de los hombres, continuará existiendo este deseo de conocer cosas más grandes. $\mathrm{Y}$ este deseo encuentra en la religión la manera más obvia de satisfacerse ${ }^{10}$.

Sunyer, en canvi, agafa la màxima il.lustrada i la porta al límit. «Tingues coratge de servir-te del teu propi enteniment», deia el solitari de Koenigsberg, i si t'equivoques, torna a intentar-ho. No siguis tan arrogant de creure que, pel sol fet de pensar per tu mateix, no t'equivocaràs. Tens moltes possibilitats d'equivocar-te la majoria de les vegades, però, si no vols errar, has de fer-ho d'aquesta manera. En definitiva, es tracta de pensar sense fonaments. En paraules del filòsof francès Jean-Marie Guyau, arriscar-se a formular hipòtesis, encara que aquestes siguin només hipotètiques ${ }^{11}$. De fet, cal que ho siguin, si no volem caure en un nou dogmatisme.

Això no fou llavors, ni és avui, gens facil d'acceptar per la supèrbia que dóna el saber; per aquesta raó, la postura de Sunyer va fer trontollar més del compte les estructures intel.lectuals i polítiques del panorama del seu temps, tan acostumades a la hipocresia del «gràcies a Déu, no crec en Déu».

El materialisme de Sunyer és, doncs, un materialisme que es distingeix dels materialistes com La Mettrie i el seu «home màquina» per l'aportació d'un clar component social; perquè, malgrat que se sosté en les formes del coneixement establertes pels materialistes del segle XVIII, la concepció de Sunyer vincula l'ateisme a la crítica social.

No pot ser que un Déu totpoderós permeti les injustícies que hi ha en el món. Aquesta és la idea-força que sosté Sunyer en el seu text i que el fa diferent,

9. Ibidem, p. 68.

10. MiLl (1986).

11. GUYAU (1889). 
tant dels esmentats materialistes del segle XVIII com del pensament social de la primera meitat del segle XIX, és a dir, de l'anomenat socialisme romàntic ${ }^{12}$, del qual Sunyer formà part en una primera època. Ara, en aquest escrit, fa una capitulació del seu passat cabetià: «No soñemos en fábricas imposibles, en fabulosas torres de Babel con las que escalar un cielo que es mentira» ${ }^{13}$.

«Estamos solos, nadie viene a socorrernos» ${ }^{14}$, diu en un altre moment de l'escrit. Idea semblant a la del seu contemporani Guyau, quan afirma que el timó de la nau està trencat o potser no n'hi ha hagut mai cap. Aquesta situació, segons Sunyer, no és ni bona ni dolenta; és quelcom més que això, és el fet inqüestionable de la radical soledat en què els humans es troben i per la qual són destinats, sota pena de desaparèixer, a crear del no-res el seu propi món.

Més que no amb els materialistes vuitcentistes i amb el socialisme romàntic, hauríem de vincular el pensament de Sunyer amb la critica de la religió de Feuerbach, a través del pensament de Bakunin. Vincular el seu pensament amb el corrent que, en la necessitat d'establir un canvi en la manera de fer filosofia, hi veia l'única alternativa que a aquesta li quedava per continuar existint. Diu Feuerbach:

La política s'ha de convertir en la nostra religió, però només ho podrà fer si som posseïdors d'un principi suprem [...] Aquest principi no és altre - expressat de manera negativa - que l'ateisme: abandonament d'un Déu diferent a l'home ${ }^{15}$.

En paraules de Sunyer:

Os robo el sentimiento divino ilusorio, absurdo, anticientífico, y os pongo en posesión en cambio del sentimiento humano, sensato, natural, positivo ${ }^{16}$.

Sunyer s'adscriurà clarament a la nova filosofia preconitzada per Feuerbach: «La nova filosofia és dissolució completa, absoluta i no contradictòria de la teologia en l'antropologia» ${ }^{17}$. I per a Bakunin: "La existencia de Dios implica la abdicación de la razón y de la justicia humana, es la negación de la libertad humana y concluye, necesariamente, en una esclavitud no sólo teórica sino práctica» ${ }^{18}$.

En definitiva, si pensar sense fonaments només comporta, tal com assenyala Diego Núñez al seu llibre La mentalidad positiva en España,

la desfundamentación del edificio moral, con sus inevitables consecuencias en todas las esferas de la conducta humana, tanto jurídica, como política y social ${ }^{19}$,
12. AleXANDrian (1983).
13. SUNYER (2007), p. 69.
14. SUNYER (2007), p. 79.
15. FEUERBACH (1842).
16. SUNYER (2007), p. 70.
17. FEUERBACH (1843).
18. BAKUNIN (1868).
19. NuÑEZ (1975), p. 39. 
és fácil veure-hi una raó per la qual el personatge de Sunyer-pensador és un bon exemple que explicaria certs aspectes de la nostra tradició de pensament, com ara que, des del segle XIX, tot trobar-se emparentada amb els més importants corrents europeus, no han acabat d'integrar-s'hi del tot. I això, sense oblidar «la manca d'ambició", tal com diu amb paraules entenedores Pi i Sunyer, besnét del nostre autor, al seu escrit biogràfic La novel.la del besavi. Un inevitable conformisme plàcid que afectà certs sectors que, a pesar de posseir les condicions adients, no les van acabar de concretar en un pensament fort.

Cal no oblidar tampoc una voluntària omissió per part dels que n'han escrit la història ${ }^{20}$; tal com ho demostra el manteniment, encara als nostres dies, del concepte "heterodox" per anomenar certs autors que no caben o no volen cabre en un cànon esquifit i vacil.lant. En el cas concret de Sunyer, és clar que encara avui, especialment per l' «heterodòxia» que el seu pensament representa, s'evidencia com un autor a tenir en compte per explicar una part important de la tradició de pensament polític al segle XIX.

\section{Bibliografia}

AlEXANDRIAN, S. (1983). El socialismo romántico. Barcelona: Laia.

Artal, F.; Gabriel, P.; Lluch, E.; Roca, F. (a cura de) (1979). Ictineu. Diccionari de les ciències de la societat als Països Catalans. Barcelona: Edicions 62.

BAKUnIN, M. (1979). Federalismo, socialismo y antiteologismo. Madrid: Ediciones de La Piqueta.

Bourdil, P-Y. (1989). Le Dieu des philosophes. Paris: Cerf.

DONOSO CORTÉs, J. (1970). Obras completas. Madrid: BAC.

Fernández Sebastián, J.; Fuentes, J. F. (dirs.) (2002) Diccionario político y social del siglo XIX español. Madrid: Alianza Universidad.

FEUERBACH, L. (1984). «Principis de la filosofia de futur» a Manifestos antropologics. Barcelona: Laia.

- (1984). «Necessitat d'un canvi» a Manifestos antropològics. Barcelona: Laia.

GAUCHET, M. (2006). El desencantamiento del mundo. Una historia política de la religión. Madrid: Trotta.

GUYAU, J-M. (1889). L'irréligion de l'avenir. París: Alcan.

MiLL, J. S. (1986). Tres ensayos sobre la religión. Madrid: Alianza Editorial.

NúÑEZ, D. (1975). La mentalidad positiva en España. Madrid: Ediciones de la Universidad Autónoma de Madrid.

Pi I SunYer, A. (1967). La novel.la del besavi. Barcelona: Pòrtic.

SÁNCHEZ MARTíneZ, G. (1987). Guerra a Dios, a la tisis y a los reyes: Francisco Sunyer y Capdevila, una propuesta materialista para la segunda mitad del siglo XIX español. Madrid: Ediciones de la UAM.

SunYer CAPDevila, F. Tratado popular de la tisis, Madrid: Ribadeneyra, 1872.

- (2007). Dios. Barcelona: Cedel.

20. Sunyer no apareix, per exemple, mencionat en el llibre de Federico Urales, La evolución de la Filosofia en España, Barcelona: Ediciones de Cultura Popular, 1968 (publicat per primera vegada a la Revista Blanca, entre el 1900 i el 1902); ni tampoc ho fa en el llibre de Norbert Bilbeny, Filosofia contemporània a Catalunya. Barcelona: Edhasa, 1985. 
URALES, F. (1968). La evolución de la Filosofía en España. Barcelona: Ediciones de Cultura Popular.

VENTURA, J. (1976). Els heretges catalans. Barcelona: Selecta.

VINYES, R. (1989). La presència ignorada. La cultura comunista a Catalunya (1840-1931). Barcelona: Edicions 62. 